Uroku ksiqzoe dodaja właściwości stylu ks.W.Kan1, dzięki któremu materiat $w$ niej zawarty odblerany jest z duzym zainteresowaniem. Niektóre jednak porównanta sq moze zbyt ezęsto powtarzane, np.: /"Didache"/ - "p e r l a wczesnego plémienniotwa" /s.13/, "List do Diogneta to p e r a w Iiteraturze młodego Kośc1oła" /s.24/, "0 modlitwie" - p e r a wóród dziez wielkiego aleksandryjczyka" /8.33/. Swiadoza one jednak - zachwycie Autora nad literatura patrystyczną. Przyblizaja nam ja równiez bezposrednie odniesienta do historil 1 iteratury polskiej: J.Kochanowskiego/s.41/, A.Mickiewioza /s.52/, J.Długosza 1 bł. Jadwigi Królowej Polski /s.93/.

W "Przedmowie" odwołuje sie Ksiądz Profesor do swej seril "Głos Tradycji" określająo ją Jako wybrane z Patrologi1 "perły" /8.5/. Połqczenie "Głosu Tradycj1" 1 "Sw1adków Tradycj1" dałoby polskie "portrety" 0jców Kościoła" 1lustrowane własnymi przekładami loh autora. Ze względu na niewlelk1 nakład zarówno "Głogu Tradycj1", Jak 1 "Swiadków...", a przede wszystk1m zo względu na $1 \mathrm{ch}$ wartośc, uzasadnione byłoby ich nowe opracowanie oraz wydanie nakiadzie, który by umozliwiał ioh osiqgnięcie rszystkim zalnteresowanym. Nakład bowien 100 ozy 400 egzemplarzy ozyni je trudno dostępnymi "perłani" polskim piémienniotwie patrystyoznym.

\title{
Czeskaw Mazur
}

\section{Q108 Tradyo11. TIum, 1 oprac, ks. Wojoloch Kania. I-VIII, Tarnów 1980-1983, Nakzadem autora.}

Jest to seria broszur /10x14/ z tłumaozonyml tekstami patrystyoznyi, wydawana na wzór włoskich "fiorett1 patristic1" angielskich "pooketbooks", ozy franouskich "livres de poohe". Kazda z nich posiada odpowiadajao treśot 1lustrowana okładke, krótki wstęp 1 eple rzeczy, co w sumie budzi zainteresowante oraz zachęca do niedługiej 1 nienuzącej lektury. Twórǫ tego oryginalnego przedsięziøola jest ks.dr hab. Wojoleoh Kania, 
profesor Wyzszego Seminarium Duohownego w Tarnowie, znany tłumaoz patrystycznyoh pism greckioh 1 łaoinsicich, a od $r .1973$ pierwszy 1 jedyny w Polsce starozytnych ohrześcijanskioh tekstów syryjskioh, które nie tylko przekłada, ale często na własny koszt wydaje. Znane sa wszystkim sympatykom antyku chrześoljańskiego jego zapaz 1 niezmożona gorliwość $w$ propagowaniu mý́l1 patrystycznej oraz piękny jezyk jego przekładów, choó tym ostatnim nte brak ozasem usterek pod względem dokładnośo1, szozególnie przy podawaniu lokalizacji tłumaozonyoh tekstów orysinalnych, co utrudnia cytowante. Temu to odvaźnemu przedsiewzięolu, które autor nazwał "Głosem Tradycji" pragniemy po-

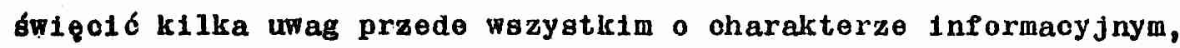
by dostrzeo 1 ocalid od zapomienia ten ciekary pomys zaznajamiania nawet mniej przygotowanych ozytelników z pismami ojéw Kośojoła, tym bardziej, ze z raoji bardzo niakiego nakładu $/ 300$ egz, / jest on truano dostepny.

I. Nauka Dwunastu Apostołów/Didachè/, Tarnów 1982, ss,16,

Jest to nowe tłumaczenie "Didachè", opublikowane po raz plerwszy w $r .1970$ /Sakramenty Viary, Kraków 1970, 131-138/。 powtórzone teraz samodzielnie z niewielkimi zmianami stylistyoznymi. Podstawa przekładu jest tekst krytyczny wydany w greokiej seril patrystyoznej: "Bibliotheke Heillenon Pateron 1" /Athenal 1955, 215-220/, oo zostało zaznaozone w plerwazej publikaoji tzumaczenla. Dziw1 więo nieco uwaga umieszczona w omawianej broszurze / $/ 8.5 / 8$ "T łumaczenie Didache na podst. SC $248 "$. 1 porównaniu z przestarzałym juz nieco przekładem ks.A.Lisieokiego /0joowio Apostolsoy, Poznar 1924, POK 1,7-40/, tłumaozonie ks. W.Kani odznacza die pieknym stylem jalk 1 słownictiven. Warto tu zasygnalizowac, ze prof. A.Swiderkówna przygotowała nowe tłumaczenie tego najstarszego wozesnoohrześcijańskiego pozabiblijnego dokumentu, ktory ukaze sie drukiem najpierw w VII tomie: "Ojoowie zywi", a następnịe w seril "Pısma Staroohrześcijańskioh Pisarzy".

II. Sw. Cyryl Jerozolimski, Katecheza o Mszy świetel. Tarnów 1982, 89, 16,

Równię 1 w tyı wypadku mamy do ozynienia z przedrukiem 
tłunaczenia $V$ Katechezy mystagogicznej sir. Cyryla Jerozolimskiego / $+386 /$, publikowanego weześniej juz ozterokrotnie /"Currenda" 107/1957/618-623; A.Bober, Antologia patrystyozna, Kraków 1965, 123-127; śr. Cyryl Jerozolimsk1, Katechezy, tłum. ii.Kania, Warszawa 1973, PSP 9, 317-323; ks. M.Mlchalsk1, Antologia literatury patrystycznej, II, Warszawa 1982,336-339/. Warto tu podkreślić, ż jest to jedyne uzywane obeonte polskie tłumaczente tej katechezy, wydarane az p1ectokrotnie, co z jednej strony może świadczyć o dobrym 1 zadawalajacym wszystkioh przelsładzlo, z drugiej zaś o braku zainteresowania Polakón twórozościa tego starozytnego duszpasterza, mimo iź na tym polu mamy pewne tradyoje, gdyz plerwszym wydaroa katechez mystagogloznych był warmiński kanonik Jan Grodecki Aliedeń 1560/, który w $1564 \mathrm{r}$. przełozył je na Jezyk łacińsk1; w r.1562 wydawał je równiez Stanisław Hozjusz. Obok tokstu V Katechezy my.stagogicznej omawiana broszura zawiera na stronach 14-15 fragment IV Katechezy mystagogicznej/rozdz.2-3, 5-6, 9/ zatytułowany: "Clało 1 Krew Pańska" /równiez publikowany wcześniej: "Currenda" 108/1958/361-363; A.Bober, Antologia patrystyczna, dz.cyt. 122-123; PSP 9, 314-316; Molichalsk1, Antologia literatury patrystycznej, dz.oyt. 334-336/. Szkoda, ze 2'zumacz nie wapomniaz nigdzie, ze w.wydawanej broszurze publikuje oatq $V 1$ eragmenty IV Katechezy mystagogicznej, jak róiniez nie zaznaczy przynajmniej kropkani opuszczonych części tej ostatniej. Takze przypis odnośnie tekstu oryginalnogo /s.3/: "PG 33,331-1180", wydaje sie być zbyt ogólny $i$ niedokładny, bo odnosi sie do wszystkioh katechez /mieszcza sie : PG 33, 331-1128,- mylnio podano: PG 33,331-1180/, a nie do publikowanyoh w broszurco $/$ IV myst. $=$ PG 33, 1007-1105; V myst. = PG 33, 1109-1128/. Noźo warto by pomyśleć o nowym przekładzio katechez mystagogicanyoh w oparoiu o ich nowy tekst krytyozny opracowany przez A.Piédagnela /Catéohèses mystagogiques, Paris 1966, SCh 126, 82 174, IV=ss.134-144, Vass, 146-174/. Przekład katochez zawartyoh w omawianej broszurze, w porównaniu z poprzednimi jego wydaniami, jest lekko stylizowany 1 posiada tytuły loh poszczególnyoh części, co zapewnia przejrzystość 1 zaohęca do ozytania. Na koniec chotelibyśny zwrócié uwage na pewne nleśolsłości, byó 
może drukarskie, jakio sie zakradły $w$ tłunaczeniu IV Katechezy mystagogicznej. W niektórych wydaniach/"Curronda", Antologia patrystycznd, nasza broszura/ akapit 6 brzmi zgodnio z tekstem oryginalnym /PG 33,1101, SCh 126, 138/ następująoo:"Nie patrz więo na chleb 1 wino jak na czysto ziemskie rzeczy". W innych natomiast /PSP 9,315; Antologia 1iteratury patrystycznej 335/ wiorsz ton brzmi: "Nie patrz wieo na ohleb 1 klelich jak na czysto ziemskie rzeczy". Podobnie w akapicie 9 pierwszy jego wiersz wi pewnych wydaniach /"Currenda"; PSP 9,316; Antologia 11teratury patrystycznej $335 /$ brzmi zgodnie $z$ tekster oryginalnym /PG 33,1104; SCh 126,144/: Wiedząc już 1 wierzqc, żo to, oo wyglada na chleb, nie jest wcale chlebem, choć smak na to wskazuje, lecz Ciałem Chrystusa, 1 to, co mygląda na wino, nie jest winem, choolaz ma smak wina, ale Krwia Chrystusa", a w

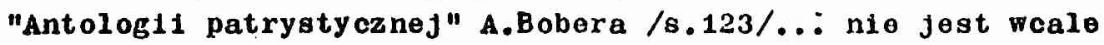
chlebem chod znak na to wslcazuje, ... nie jest winem, chociaz ma smak wina", -w omawianej zas przez nas broszurze /s.15/: ... nie jest wcale ohlebem, choć znak na to wskazuje .... nio jost winem, choć ma znak wina". Przy ponownym wydaraniu tej katechozy warto by wigo ujodnolició joj tekst.

\section{Ste Cyryl Aleksandryjski, Ku czc1 Bogarodzicy, Tar- nów 1982, 88, 16,}

Tytuł broszury nie jest w pełni adokwatny, bo zawiora ona oprócz publikowanej Juź woześntej IV Homllii efeskioj /PG 77,992-996; Sw. Cyryl Aleksandryjski - lykład prawdziwej wary, W obronie tytułu "Bogarodzica", Homilio oPeskie, tłum. W.Kania, Warszawa 1980, PSP 18, 238-241/ dwa tłumaczone po raz pierwszy lrótkie listy Cyryla /444/ do kleru 1 ludu aleksandryjskiego/Ep.20, PG TT, 128-129; Ep. 25, PG 7T, 137-140/, w których jednak nie ma zadnej wzalanki maryjnoj; pierwszy ptgany przed Soborem Efeskim, drugi zaś po nim,informuje o jego deoyzjach. Główny więc trzon broszury stanowi dyskusyjna co do autentyczności /odrzuca Ją E.Sohwartz, W:Aota Conciliorum 0ecumenicorum $I, I, 4$, a.XXV; bronią jej: R.Caro, La Homilética Mariana Griega on el Siglo V, Marian Library Studies 4/, Ir, Dayton 1972, 269-283; M.Santer, The Autorship and Occaston of Cyril of Aleksandria's Sermon on tho Virgin /Hor.Div.IV/, 
StP 12/1975/144-150/ IV Efeska homllia maryjna, nazywana "najsławniejszym kazaniom maryjnym w starożytności" /Quasten/, które nasz Tłumacz,idąc za opinią większości patrologów, przypisuje Cyrylowi /por. ks.W.Kania, Autentyczność homilil efeskiej "Ku czci Bogarodztcy", w: Maria w tajomnicy Chrystusa. Alta sympozjum patrystyozno-dogmatycznego w Niepokalanowie 14-16 IX 1981 - w druku/. Warto tu przypomnied, że jest to drugie polskie tłumaczente tej mowy /pierwsze zob. A.Bober, Mowa soborowa o Maryi Bogarodzloy, TP 19/1965/nr 33, B.1, 15 sierpnia = Antologia patrystyczna 140-142/. Przekład homili1 zawartej w omarianej broszurze, piekny 1 pełon głebokiego patosu, posiada dobrze zaznaczong lokalizaoje, podobnie jak dwa dołączone tłumaczenia listów /dokonane w oparoiu o tekst Migno'a/. Między nim jednak a pierwszyın jego wydaniem w PSP zakradły sie juz pewne rozbieźności, które moźnaby ostatecznie wytłumaczy c wzgleqdami stylistycznymi: rozdz.I /PG 77, 992B/8

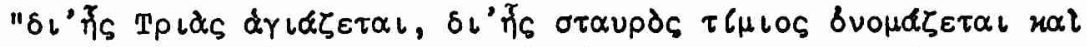

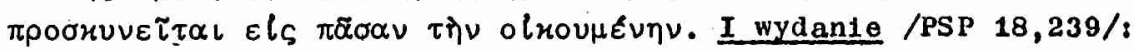
"Dziqki Tobie odbiera cześć Trójoa, Dzięki Tobie w całym świecle hołd odbiera krzyz drogocenny". II wydanie /broszura 9.7/: Dzięki Tobie wielbimy Trójce Swięta, Dzięki Tobie ozoimy na oałej ziemi krzyz drogocenny, Dzięki Tobie raduje sie niebo". A.Bober /Antologia patrystyczna 140/: "Dzioki Tobie wielbimy Trójce, dzięki Tobie raduje się nłebo".

IV. Sw, Efrem, Pieśn Pustyni Syryjskiej, Tarnów 1980, s8,28.

Broszura zawiera, jak stwierdza sam Tłumacz we wstepie, "7 pieśni liturgloznych" áw. Efrema Syryjozyka $/+373 /$, które oprócz dwóch, nie były jeszcze znane jezykowi polskiemu. Ks. 1 .Kania, jedyny jak dotąd $\$$ Polsoe tłumacz eyryjskiej literatury patrystycznej /Por. Sw.Efrem, Cyryllonas, Balaj - Wybrane pieśni 1 poematy syryjskie, tłum. W.Kania, Warszawa 1973, PSP 11; Ojcowie Koścloza grecoy 1 syryjsoy. Teksty o llatce Bozej, Niepokalanów 1981, 33-73 = 8 piośni maryjnych św. Efrema w tłumaczeniu ks. W.Kan 1 /, powielksza przez nie 1 tak Juz pokaźna liczbe przełozonyoh starożytnych poematów eyryjskioh. Lokal1zacja plośni zawartyoh w broszurze umieszozona jest w spisio 
rzeczy. A oto 1ch tytuły: ss.4-8: Skrócona Pieśrí o líaryi 1 Mędrcach /Csco 186,209-216/. Cała umieszczona jest ve wspomnianym Juz XI tomte PSP, 32-40. Szkoda, ze nie zaznaczono przynajmnlej kropkrami, w którym miejscu 1le strof zostało opuszczonyoh; - s8. 9-10: Pieśń o ukrzyżowanłu Pana/Aug.Denk.V,361/; - s8. 10-14: skrócona P1eśń o Baranku /CSCO 298,6-7, 12-14/; - ss. 14-18: P1eśń $\nabla 1$ lelkanocna /CSCO 298,82-85/; - ss. 19-22: Pieśn o Duchu Swiętym /CSCo 159,225-228/; - ss. 22-24: Pieśń - Najḱwiętszej Pannio/L 2,523-527/ publikowana przez Tłumacza woześniej dwukrotnie /PSP 11,30-32 oraz,0jcowte Kościoła greccy 1 syryjsoy"37-39/mimo, iz nie wszysoy uznaja jej autentyczność /uznaja ja: G.Bosio, Iniziazione al Padri, II, Torino 1964, 188 oraz Th.Lamy, S.Ephraem hymni et sermones, Hochlinlae 1902, II, 523; do dubia zalicza ja J.Ortiz do Urbina, Patrologia syriaca, Romae $1965^{2}, 73$ oraz R.Beck, Die llariologle dex echten Schrifţen Ephraems, "Ortens Christianus" 40 /1954/22-40/i - \$8.25-28: Pieśń o dniu śmierci i dntu zmartwychwstania/CSc0 240,134-135/. Prozentowane wiec w broszurze pieśni nie sa jednolite, ale daja moźność poznać rózne ich typy 1 tematykę. Hracająo do lokalizacji, dobrze byłoby objaśnié gdziés stosowane w niej skróty. Jeśli boviem wóród patrologów znany jest CSCo /Corpus Scriptorum Christianorum orientalium/, to nie mająoy do czynienia z dziełami św. Efrena nie zatwo zrozumie, ze "L" zastosowane przy lokalizacji szóstej pieśni oznacza wydante Th.Lamy'ogo/S. Ephraemi hymni et sermones, I-IV, Mechliniae 1902 - J.Ortiz de Urbina oznacza go: LA/, a juź ohyba nikt nie odgadnie lokalizacji "Pieśni o ukrzyżowan1u" oznaczonej: "Aug.Denkw. V,361".

V. Sw.Efrem, Wszystka plekna josteś, Tarnów 1980, ss.24.

if przeolwienstivie do poprzednlej, ta broszura zawlera Juz 5 jednotematyoznyoh, tłunaczonych po raz pierwszy na jezyk polski, pieśni św. Efrema, pośwįoonych wyłacznie Matoe Bożej. Wszystkie opublikowaz autor po raz drugi w $1981 \mathrm{r}$. w swej patryetycznej antologil maryjnej: "Ojoowio Kościoła greccy 1 ayryjsoy. Teksty o latce Bożej"/niektóre pod zmienionym ty tukeun/. Trzeba tu powtórzyó uwage Tłumacza zanieszczoną we wstępie, ze św. Efrem by jednym z pierwszych autorów chrześ- 
c1jańskich, którzy Matce Bozej zaczęl1 poświęać samodzielne dzieła, pieśni lub poematy. A oto wykaz zamieszczonych w broszurze pieśni: ss. 5-8: skrócona o 4 strofy Pieśń ku czci Dziewicy Llaryi /CSco 186,191-199/, wydana pózntej w całości w antologii ze zmientonym tytukem: "Pieśn o Najówiętgzej Pannie" /Ojcowie Kościoła grecoy i syryjsoy 33-36/; - s8.9-11: Pieśń - Ewio 1 Maryi /CSco 198,87-90/, powtórzona w antologii /8s. 40-43/; - 8s.12-16: pieśń "Uboga - Matką Bogatego"/CSCo 186, 199-203/ wydana ponownie w antologit ze zmienionym tytuzem: "Pieśn Maryi do Boskiego Dzlecięcia"/8s.44-48/i - 8s.16-18: skrócony o połowe tłunaczony z greckiego poemat "Nieskalana" /AS Op.Gr. 3,575-577/, wydany późntej w całośc1 ze zintentonym tytułem: "IKu chwale Bozej Rodziolelki Dziewicy Maryi" w antologi1/ss.69-72/; - ss. 18-22: tłumaczony z greckiego z drobnymi opuszczentamí wzruszajacy poemat "Zale Maryi nad cierpiacym Jezusem" /AS Op.Gr 2,574-575/, powtórzony w całości z powaznymi zmiananl stylistycznymi w antologii /8s.73-75/. Naleza sie tu słowa pełnego uznania dla Czcigodnego Tłumacza za udostępnienie w sposób tak prosty 1 bezpośredni próbek egzotyoznej dla nas starozytnej poezji syryjskiej. Zyczyć by sobie nalezało, by w dalszych broszuraoh serii "Głos Tradycji" pojawiały się równié rragmenty zapowiedzianych przekładów "Pieśni o perle" 1 "Pieśni nisibijstrich".

\section{Iyun "Akathistos", Tarnów 1983, ss,16.}

Hyın "Akathistos" to jeden z najpiekniejszych zabytkow liturgii bizantyjskiej i poezji ohrześcijariskiej, wyrosły na gruncie maryjnej pobożności greckich i syryjskich ojeów Kośoloła. Obok najbardziej dzí́ znanego 1 powszechnie uźywanego jego tłumaczenia H.Bednarza/"Znak" 131/1965/636-648 = A.Bober, Antologia patrystyczna, Kraków 1965,516-530 = oddzielne wydanie 00. Marianow: Akatyst ku czci Bogarodzicy. Starozytny liturgiozny hymn maryjny z dodatkiem oflojow towarzyszacyoh. Red.S.J. Gajek, Irzym 1980, ss.107/ i nieco starszego, zapomnianego przekładu karinelity o.Smyraka Bernarda od Matk1 Bozej /Niepokalana, Kraków 1937, 20-53/ pojawta sie nowe polskie tłumaczente ks.W.Kant, publikowane najplorw w "Tarnowskich Studiach Teologicznych" /8/1981/287-293/, potem w patrystyoznej antologil 
maryjnej/"0jcowie greccy i syryjscy. Teksty o Matce Bozej", Niepokalanów 1981, 265-281/, a vreszcie oddzielnie w omawianej przez nas broszurco. Za podstarv przekładuftekst Meerssemana u H.Bednariza/ słuzyz grecki tekst Migne'a /PG 92,1335-1398/. Piękny jezylk 1 wyraźny podział na 24 strofy zachęcaja do czytania, powtarzane zaś i tekście staropolskie "Zdrowaś" nadaje hymnowl posmak przeszłośc1.

VII. Kwintus Septymiusz Florens Tertulian, 0 świadectwie duszy, Tarnów 1982, 8s.20.

Jest to pierwszy opublikowany w całości polski przekład małego apologetycznego traktatu Tertullana $/+220 /$, będącego rozwinięc1em krótkiego zdania z jego "Apologetyka" /17,6/: "0. testimonium animae naturaliter ohristianae". Dotąd boriem ta piękna filozoficzna rozprawa znana była polskicmu czytelnikowi tylko we fragmentaoh. Ostatnio pojawiz się arugi jej nowy przekład A.Guryna opublikowany $w$ XXIX tomie "Pism Starochrześcljankkioh P1sarzy". Naleza sie tu słowa pełnego uzrania dla pierwszego Tłumacza za przyswojenie jezylsow1 polskiemu tego wartośctowego, trudnego do tłunaczenta, traktatu w p1eknym jak zwykle stylu /tłumaczenie na podstawte CSEL 20, 134-143/..

\section{Sw, Plotr Chryzolog, Zródło wody zywej. Ilomil1e wybrane, Tarnóviv 1983, ss.4.0.}

Jest to najobszerniejsza broszura z calej omawianej seril, zawierajaca 5 homilif 12 katechezy malo jeszcze znanego w Polsce ów. Plotra Chryzologa $/+450 /$, lotóry pozostawiz po sobie 176 homilif i kazan. "Celen niniejszego, skromnego zreszti wyboru, stwieraza Tłumacz we wstępie, jest zwrócenie uwag 1 na te perłę literatury patrystycznej i zachęta do podjęcia trudu w przekładzie wszystki oh mów wielkiego biskupa". Nie wiele bowiem faktycznie przełozono dotychozas na język polski 2 jogo homiletyoznej twórozości /Jedynie: mowa XII o pośoie 40 - dnionym w tłun. T.Karyłowskiego, "Viara i kycie" 5/1925/ 88-90 = A.Bober, Antologia patrystyozna, Kraków 1965, 281-283; mowa CXVIII o śmierci i zmarwyohwstaniu ciał $w$ tłum. anonimowym, "Homiletyka" 31/1913/195-199 = A.Bober, J.w., 283-285; fragment mowy XCIV o nawróceniu Haril lagdaleny, A.Lober,jw., 283; fragment mowy CXLV o narodzeniu Chrystusa i Józefio, A. 
Bober,J.w.,285-286; oraz 6 mów CXL-CXIV o zwiastowaniu, woieleniu 1 narodzeniu Chrystusa w tzum. Ks. $17 . K a n i$ w: Ojoowie Koścloxa łacińscy. Teksty o Matce Bozej, II, Niepokalanów 1981, 129-148/. Talc w1ęo przekład nowyoh mów, zarartyoh w omawianej przez nas broszurze, stanowi dalszy przyczynolk do przyblizenia polekiemu czytelnikowi twórozości tego atarozytnego kaznodzie1. Podstawa przekładu by łaoiński tekst Migne'a. Szkoda tylko, ze Tłumacz nie podawał numeru przekładanej mowy, ani tez dokIadnej ich lokalizacji, zadawalając się tylko ogólnym objaínienten: "Tłumaczente na podst. PL 52,183-680" /cała twórozośd Plotra Chryzologa/. A oto zawartość omawlanej broszury: 8s.5-8: pierwsza z cztereoh homilii o zwiastowaniu Najów. Mari1 Pannie = mowa CXL /PL 52,575-577/; ss.8-13: pląta z plęciu homilit na objawienie Panskie = mowa $\mathrm{CLX} / \mathrm{PL} 52,620-622 /$; 88. 13-17: homflià o uciszeniu burzy na morzu $=$ mowa XX $/ \mathrm{PL}$. 52,253-257/; ss.18-23: szósta z sześc1u katechez o Modl1twie Pańskiej = mowa LXXII /PL 52,404-406/; 89. 24-29, druga $z$ sześoiu homilil na Znartifyohwstanie Paískie = mowa LXXIV /PL 52,408-411/; ss. 29-30: okolloznościora homilia z okazji konsekraoji Korneliusza Projekta na blskupa Forum Cornel11/p6zniejszej Imoli/ = mova $\operatorname{CLXV} / \mathrm{PL} 52,633-634 / 8$ ss. 30-40: ostatnia z sledmiu-katechez o Apostolskim Wyznaniu Wiary = mowa LXII /PL 52,371-375/. Jedynie pierwsza z wyliczonych homili1 była juź publikowana /Ojoowio Kośoloła łacínscy. 'Peksty o Niatce Bożej 129-130/, reszta tłunaczona jest na jezyk polsk1 po raz pieriszy. Oby ten dobry poczatek przyczyniz sie do ozywienla dalszego zainteresowania tym złotoustym kaznodzieja kaoińskim.

Tak oto wygląda przegliqd treśo1 poszczególnyoh broszur nowej polskiej broszurowej seril patrystycznej "Głos Iradyoji". Warto tu przypomnieć, ze na jej wzór ks.W.Kania opublikowaz równlez 3 broszury blograficzne, poświęone św. Bazylemu, św. Efremowi, św. Janowi Chryzostomowi / Pumacz niobios, Tarnów 1980, ss.24; Cytra Ducha Swiętego, Tarnów 1980,88.24; Złotousty Siewca Słowa, Tarnów 1981, ss.28/. Na zakońozenie naszyoh uwag zyczymy Twóroy. seri1 "Głos Tradyoji" dalszyoh udanyoh broszur patrystyoznych, ale w o wiele wiekszym nakładzie, by głos Ojoów Kościoła mógł docierać do wszystkich nawet mniej przygotowanych ludzi. 